\title{
Mental health in rural areas: experience in south Cambridgeshire
}

\author{
A. J. Smith and R. Ramana
}

\begin{abstract}
Mental health morbidity is percelved as being predominantly urban based. Littile is known about the health of the UK's rural residents. This paper summarises existing knowledge of rural health and social indicators. There is a relative dearth of information in this area making the application of urban-based (and biased) factors perhaps unrellable. Some rural areas have lovels of deprivation similar to urban areas, even using urban-blased factors, though they encounter spectific problems of service provision and accessibility. Currently, there seems to be no valld method of measuring rural deprivation and comparing it with urban deprivation. We highlight this inequality by describing discrepancies in day care provision between urban and rural areas.
\end{abstract}

'Classic' psychiatric literature suggests higher rates of illness in inner cities (e.g. Hare, 1956). Little is actually known of the state of mental health in the UK's rural areas, having been described as "unjustifiably neglected" (Watt et al, 1993).

There are many problems in defining both health and deprivation. Social deprivation has typically been measured using Jarman indices such as Jarman-8 scores; a composite of eight factors (Jarman, 1983, 1984). These are not above reproach. Car ownership, for example, might be considered a predictor of wealth but it needs to be placed in the context of local transport resources.

Thornicroft (1991) considered statistical models used to predict psychiatric service utilisation. The Jarman-8 indices correlated with admission rates in South-East Thames and West London (Hirsch, 1988). A 'principal component analysis' identified three main components: a general deprivation factor, a socially isolated factor and a factor reflecting psychiatric service availability. The appropriateness of Jarman-8 to a rural population has been questioned (Thornicroft et al, 1993).

Thornicroft et al, (1993) suggest that service utilisation may be higher in urban areas (Goodman et al, 1983; Keatinge, 1989) while total prevalence rates for most psychiatric disorders are probably little different between urban and rural areas (Mueller, 1981; Blazer et al, 1985; Romans-Clarkson et al, 1990). In essence those patients in inner cities devoid of family or other support networks place a disproportionate demand on the service. A case register study in Italy confirmed this (Thornicroft et al, 1993), concluding that the social environment "powerfully shapes the extent individuals initiate and sustain contact with services when unwell". Referral characteristics of general practitioners and distance from service reduce the demand (though not need) from rural areas. This has been shown in both Spain and the UK (Stansfeld et al, 1992; Vázquez-Barquero et al, 1993).

The urban bias is fuelled by the description of deprived areas in large conurbations. This is an 'ecological' problem (i.e. the assumption that regions are homogenous). There is large vartability within urban and rural areas. Phillimore \& Reading (1992), in a study in northern England, described a greater economic and social polarisation within conurbations, so while conurbations have the most deprived electoral wards in a region, they also have the most advantaged in a region. Rural areas were devoid of the worst urban-like deprivation, but also denied the areas of greatest wealth.

The Office of Population Censuses and Surveys found higher levels of psychiatric morbidity in urban areas and increased odds ratios for depressive episode, phobia and generalised anxiety disorder. However, no standardised criteria were used to rate whether an area was urban or rural; interviewers were asked to code their opinion of the type of locality (Meltzer et al, 1995).

The aim of this study is to determine the social deprivation in and around Cambridge, to see if rural and urban deprivation can be reconciled and to consider service provision and utilisation for the two populations.

\section{Local service}

Fulbourn Hospital, situated just outside Cambridge, serves a large area of South 
Cambridgeshire. Cambridge is the major city (population 109570 ), famous primarily for its university and has a large amount of light, science-based industry. It is not a conurbation and is generally devoid of post-industrial blight. The services' catchment area extends outward from the hospital to a variable distance up to 30 miles. The service is sectorised into city and rural sectors. For the rural sectors attempts have been made to provide services locally; the northern rural sector has a day care facility in Ely, in the north-east corner of the sector (and so distanced from clients in the north-west) while in the southern rural sector day care facilities exist for one day a week in four different villages. These rural day care facilities are run by social services. The health services run day care for Cambridge city and this is provided in the city. Rural residents are not barred from these facilities, but there appears a dearth of facilities in the rural areas themselves. Of 200 clients attending day care facilities in the city, 23 are from rural areas.

Other social and vocational services exist within the city: 'The Clubhouse' and The Castle' both provide social and practical support along with work rehabilitation. The young person's psychiatric service, the child and family service and the drug and alcohol service are all based within the city. Although these are open to the whole catchment area they are used mainly by urban dwellers. Clinics are predominantly run at Addenbrooke's Hospital, as is the psychotherapy department. 'Cottage hospitals' in Royston, Ely and Newmarket have closed. Community psychiatric nurses provide local care and support. The Cambridge Psychiatric Rehabilitation Service caters for a large number of severely mentally ill and has its own day centre in Cambridge city. This service is highly autonomous, operating separately from the general adult service. Eleven of 106 clients attending the day centre are currently from rural areas. We have not been able to determine any effect of migration.

Transport appears to be a major problem; the transport budget for the fiscal year 1995-1996 was set at $£ 11000$ for the north rural sector (population 110000 ) and was spent within the first four months of that year. Social services has a limited budget and so has to approve or refuse transport costs on a case-by-case basis. Urban day care comes under the remit of the health authority and a block contract with a local ambulance provider is in place.

\section{The study}

Wards in the catchment area of Fulbourn Hospital were identified. The Department of Environment definition of rural areas is used; namely electoral wards outside settlements of 10000 (Rural Development Commission, 1994). All wards were then ranked for six factors according to criteria used by Cambridgeshire County Council (1996) to identify areas of urban deprivation. Wards in the 70-80 decile scored one point, wards in the 80-90 decile scored two points and wards in the 90-100 decile scored three points. A 'composite score' for deprivation was established as the sum of the scores for each individual factor (i.e. 0 (least deprived) to 18 (maximum possible deprivation)).

Wards of equal deprivation in rural and urban areas were then compared for service utilisation rates and day care service provision. To consider problems with factors and their arbitrariness wards were also ranked according to primary care services in individual wards to illustrate how the choice of factors can drastically alter levels of perceived deprivation.

Service utilisation was derived from a one week census of contacts from June l-June 71996.

Service provision was determined by measuring number of places in day care available, either through health, social service or voluntary provision, within a four mile radius. In Cambridge it comprised the Cambridge Mental Welfare Association (100 places per week), the Cambridge Day Centre (100 places per week) and the Norfolk Street project (100 places per week). In Ely, day care comprised the Croylands Centre (100 places per week) and the Speirs project in the southern area was considered which has 20 places for one day per week in Whittlesford, Melbourne, Gamlingay and Bourn. Rural wards bordering urban areas were assumed to be able to access services within the adjacent urban areas. Clients were assumed to have no transport problems.

There is no method of measuring the 'density' or availability of services. For this exercise we were comparing wards with equal levels of deprivation. The model we proposed was for a ward where $p=$ ward population, $d=$ day care places within a four mile distance, the theoretical services use is $p \times d$, although obviously all the population could not attend all the time. Rural wards though have smaller populations and to account for this the total rural or urban population in these equal areas of deprivation was used as a denominator; if this had not been performed levels of rural service provision would have appeared even poorer. So, for urban or rural wards with equal levels of deprivation, the day places per week per thousand population was calculated as $p$ :

Day care places $=\frac{p 1 \cdot d 1+p 2 \cdot d 2+\cdots+p n \cdot d n}{p 1+p 2+\cdots+p n}$ 


\section{Findings}

Ranking of wards: Results shown in Table 1 rank wards by factors used by Cambridgeshire County Council.
Service utilisation: Results showed marginally more urban contacts but not in number of contacts per staff (Table 2).

Service provision showed more urban provision (see Fig. 1).

Table 1. Identification of deprived areas

\begin{tabular}{|c|c|c|c|c|c|c|c|c|c|c|c|c|c|}
\hline \multirow{2}{*}{$\begin{array}{l}\text { Ward } \\
\text { (population) }\end{array}$} & \multicolumn{2}{|l|}{$\mathbf{A}$} & \multicolumn{2}{|l|}{ B } & \multicolumn{2}{|l|}{ C } & \multicolumn{2}{|l|}{ D } & \multicolumn{2}{|l|}{ E } & \multicolumn{2}{|l|}{$\mathbf{F}$} & \multirow{2}{*}{$\begin{array}{l}\text { Composite } \\
\text { score }\end{array}$} \\
\hline & $\%$ & Score & $\%$ & Score & $\%$ & Score & $\%$ & Score & $\%$ & Score & $\%$ & Score & \\
\hline Market $(6600)^{\prime}$ & 62 & 3 & 17 & 3 & 9 & 2 & 12 & 3 & 35.5 & 3 & 46 & & 14 \\
\hline Arbury (7070)' & 63 & 3 & 16 & 3 & 11 & 3 & 16 & 3 & 20.5 & 2 & 48 & & 14 \\
\hline Abbey $(6850)^{\prime}$ & 63 & 3 & 17 & 3 & 11 & 3 & 11 & 3 & 21.8 & 2 & 50 & 1 & 14 \\
\hline East Chesterton (9330) ${ }^{\prime}$ & 69 & 1 & 10 & 2 & 9.7 & 3 & 15 & 3 & 22.2 & 2 & 49 & 1 & 12 \\
\hline Romsey (7950)' & 71 & & 18 & 3 & 11 & 2 & 9.8 & 2 & 18.7 & 1 & 52 & 3 & 12 \\
\hline Petersfield (8850)' & 70 & & 16 & 3 & 9.2 & 3 & 8.1 & 2 & 29.8 & 3 & 49 & 1 & 12 \\
\hline King's Hedges (7100)' & 70 & & 24 & 3 & 12 & 3 & 11 & 3 & 20.2 & 1 & 45 & & 10 \\
\hline Coleridge (7590)' & 59 & 3 & 14 & 2 & 7.1 & 1 & 9.5 & 2 & 19.8 & 1 & 50 & 2 & 9 \\
\hline Trumpington (7730)' & 62 & 3 & 11 & 2 & 6.3 & 1 & 4.7 & & 19.5 & $i$ & 44 & & 7 \\
\hline Ely North (3941)' & 71 & & 9.4 & 2 & 7.5 & 2 & 7.4 & 1 & 22.6 & 2 & 44 & & 7 \\
\hline $\begin{array}{l}\text { West Chestertón } \\
(7890)^{\prime}\end{array}$ & 69 & 1 & 8.4 & 1 & 9.1 & 3 & 3.9 & & 23.9 & 2 & 45 & & 7 \\
\hline Meldreth (2146) & 73 & & 5.4 & & 7.9 & 2 & 11 & 3 & 11.8 & & 50 & 2 & 7 \\
\hline Witchford (1628) & 71 & & 3 & & 6.7 & 1 & 8.4 & 2 & 32 & 3 & 38 & & 6 \\
\hline Newnham (9200)' & 63 & 2 & 9.1 & 1 & 5.4 & & 5.7 & & 29.7 & 3 & 43 & & 6 \\
\hline Harston (1949) & 72 & & 5.6 & & 4 & & 0.7 & & 29.4 & 3 & 51 & 3 & 6 \\
\hline Whittlesford (2114) & 76 & & 4.4 & & 4.1 & & 1.3 & & 28.1 & 3 & 52 & 3 & 6 \\
\hline Ely South $(2441)^{\prime}$ & 61 & 3 & 13 & 2 & 6 & & 3.6 & & 15.2 & & 41 & & 5 \\
\hline Castle $(8280)^{\prime}$ & 68 & 2 & 7.4 & & 7.3 & 2 & 6.5 & 1 & 10.2 & & 41 & & 5 \\
\hline Cherry Hinton (7180)' & 70 & $\overline{1}$ & 11 & 2 & 5.3 & & 9.3 & 2 & 9.1 & & 43 & & 5 \\
\hline Littleport (6271) & 68 & 1 & 7.6 & & 7.7 & 2 & 8.1 & 2 & 14.7 & & 47 & & 5 \\
\hline Arrington (1369) & 74 & & 1.2 & & 7.5 & 2 & 2.2 & & 33.3 & 3 & 47 & & 5 \\
\hline Girton (3202) & 62 & 3 & 6.7 & & 3.7 & & 3.9 & & 7.9 & & 50 & 2 & 5 \\
\hline Barrington (1690) & 77 & & 5.4 & & 7.9 & 2 & 4.5 & & 20.7 & 2 & 39 & & 4 \\
\hline Willingham (3278) & 75 & & 6.1 & & 4.7 & & 9.2 & 2 & 11.7 & & 50 & 2 & 4 \\
\hline Fulbourn (4281) & 80 & & 5.5 & & 3.7 & & 8.1 & 1 & 15 & & 51 & 3 & 4 \\
\hline Haslingfield (1676) & 74 & & 5.5 & & 6.4 & 1 & 2.2 & & 0 & & 53 & 3 & 4 \\
\hline Teversham (3437) & 82 & & 15 & 3 & 6.1 & & 6.1 & & 14 & & 43 & & 3 \\
\hline Great Shelford (3968) & 65 & 2 & 8.6 & 1 & 4.7 & & 4.7 & & 9.4 & & 44 & & 3 \\
\hline Milton (3960) & 85 & & 9 & 1 & 4.9 & & 6.2 & 1 & 20.5 & 1 & 46 & & 3 \\
\hline Queen Edith's (7950)' & 65 & 2 & 5.7 & & 6.2 & 1 & 5.3 & & 8.9 & & 48 & & 3 \\
\hline Haddenham (3817) & 70 & & 5.2 & & 6.1 & & 11 & 3 & 16.3 & & 48 & & 3 \\
\hline Bassingbourn (3727) & 77 & & 7.8 & 1 & 7.1 & 1 & 2.6 & & 9.8 & & 49 & 1 & 3 \\
\hline $\begin{array}{l}\text { The Wilbrahams } \\
\text { (1418) }\end{array}$ & 73 & & 6.8 & & 4.7 & & 5.3 & & 19.4 & 1 & 50 & 2 & 3 \\
\hline Bourn (1820) & 73 & & 5.4 & & 5.5 & & 4.7 & & 4.8 & & 51 & 3 & 3 \\
\hline Sawston (7134) & 75 & & 6 & & 4.2 & & 3.7 & & 9.7 & & 52 & 3 & 3 \\
\hline Swavesey (1905) & 77 & & 6.7 & & 3.7 & & 3.2 & & 9.7 & & 55 & 3 & 3 \\
\hline Abington (1960) & 74 & & 6.4 & & 6.9 & 1 & 4.1 & & 18.4 & 1 & 36 & & 2 \\
\hline Coton (1491) & 72 & & 4.2 & & 5.6 & & 3.3 & & 27.3 & 2 & 41 & & 2 \\
\hline Barton (1409) & 67 & 2 & 6.6 & & 2.8 & & 4.9 & & 8 & & 41 & & 2 \\
\hline Cheveley (2185) & 68 & 2 & 4.8 & & 4 & & 4.5 & & 6.5 & & 43 & & 2 \\
\hline Ely West (4707)' & 68 & 2 & 6.4 & & 5.3 & & 3.1 & & 12.4 & & 48 & & 2 \\
\hline Hardwick (2490) & 83 & & 3.6 & & 3 & & 1.5 & & 16.1 & & 51 & 2 & 2 \\
\hline
\end{tabular}

A. households with no earners; B, dependent children living in lone parent families; $C$, male unemployment ages 16-65; D, of children living in overcrowded households; $E$, 16-19 year olds not in education; $F$, over 75s with limiting long-term illness. Scores are three for presence in bottom decile, two for presence in 80-90 decile, one for presence in the 70-80 decile: the total composite score is the sum of the scores.

Eleven other wards (all rural) scored one on their composite score; 19 other wards (all rural) scored zero on their composite score.

1. Urban (all other deprived areas rural). 
Table 2. Contacts with community mental health teams per sector (census week 1-7 June 1996)

\begin{tabular}{lll}
\hline & Contacts & $\begin{array}{l}\text { Contacts per } \\
\text { number of staff } \\
\text { per week }\end{array}$ \\
\hline North Cambridge city & 118 & 23.6 \\
South Cambridge city & 102 & 34 \\
North rural & 91 & 22.75 \\
South rural & 90 & 22.5 \\
\hline
\end{tabular}

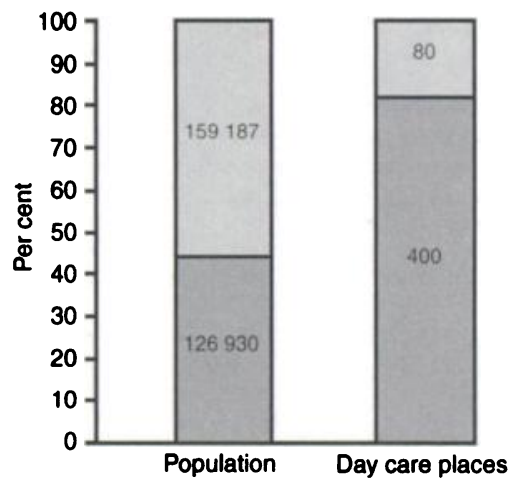

Figure 1. Day care places per 1000 population. 口. rural; $\square$, urban.

However, at every level of comparable social deprivation, urban areas did consistently better in terms of service provision (see Fig. 2).

\section{Comment}

The results clearly show that the areas of greatest social deprivation are in the urban

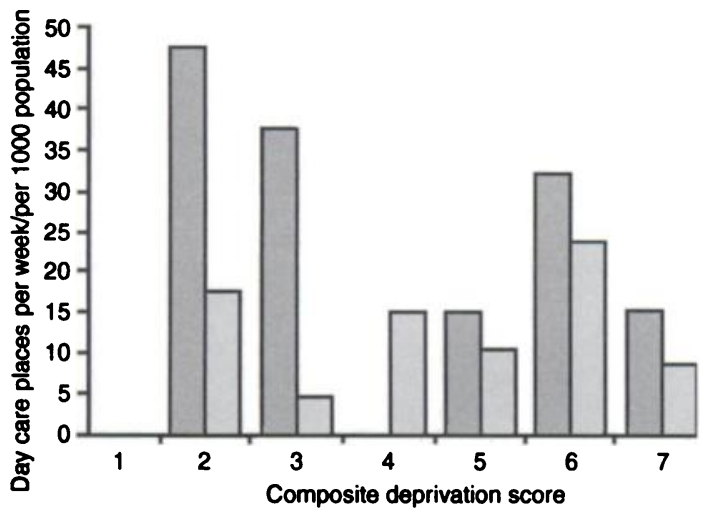

Figure 2. Day care service provision: urban v. rural, controlled for deprivation and population 口. urban; $\boldsymbol{\square}$, rural areas, considering the urban-based factors used in this analysis. However, if factors associated with rural deprivation had been used the picture could have been reversed. We calculated density of general practitioner provision for all wards and this reverses the picture (Table 3 ).

This illustrates the problem of reconciling urban and rural deprivation to enable fair and meaningful comparisons. Urban deprivation indices are appropriate for comparing across urban areas, but extrapolation to rural areas may be inappropriate. Cambridgeshire County Council have calculated levels of rural deprivation (1996), using factors such as no general

Table 3. Density of primary care provision

\begin{tabular}{lcc}
\hline Ward (population)' & GPs & $\begin{array}{l}\text { Population per } \\
\text { GP }\end{array}$ \\
\hline Bourn (1820) & 4 & 455 \\
Dullinghams (1982) & 3 & 661 \\
Linton (4100) & 6 & 683 \\
Haslingfield (1676) & 2 & 838 \\
Longstanton (2014) & 2 & 1007 \\
Arrington (1369) & 1 & 1369 \\
Downham (2934) & 2 & 1467 \\
Ely Comp (11 089)' & 7 & 1585 \\
Cambridge Comp (109 570)' & 69 & 1588 \\
Castle Camps (1765) & 1 & 1765 \\
Bar Hill (5689) & 3 & 1896 \\
Swavesey (1905) & 1 & 1905 \\
Stretham (1931) & 1 & 1931 \\
Harston (1949) & 1 & 1949 \\
Isleham (1951) & 1 & 1951 \\
Elsworth (1997) & 1 & 1997 \\
Woodditton (2020) & 1 & 2020 \\
Orwell (2108) & 1 & 2108 \\
Fulbourn (4281) & 2 & 2140 \\
Meldreth (2146) & 1 & 2146 \\
Comberton (2311) & 1 & 2311 \\
Burwell (4634) & 2 & 2317 \\
Cottenham (4840) & 2 & 2420 \\
Over (2432) & 1 & 2432 \\
Bottisham (2568) & 1 & 2568 \\
Fordham (3026) & 1 & 3026 \\
Girton (3202) & 1 & 3202 \\
Willingham (3278) & 1 & 3278 \\
Gamlingay (3380) & 1 & 3380 \\
Teversham (3437) & 1 & 3437 \\
Histon (7177) & 2 & 3588 \\
Sutton (3692) & 1 & 3692 \\
Bassingbourn (3727) & 1 & 3727 \\
Milton (3960) & 1 & 3960 \\
Great Shelford (3968) & 1 & 3968 \\
Melbourn (3976) & 1 & 3976 \\
Waterbeach (4662) & 1 & 4662 \\
Littleport (6271) & 1 & 6271 \\
Sawston (7134) & 1 & 7134 \\
Soham (8365) & 1 & 8365 \\
\hline GP gengr & \\
\hline
\end{tabular}

GP, general practitioners. Eighteen wards (all rural) have no GP surgery within their boundaries. 
practitioner surgery, no local shops, levels of public transport and so on; these factors are largely meaningless in urban areas. However, even if we accept the appropriateness of urbanbased deprivation factors, then there are still some rural areas that are worse than or equal to some urban areas. The 'ecological' argument is flawed; urban areas have the wards with the highest levels of deprivation but it does not follow that living anywhere in the city is detrimental to one's health.

Controlling for social deprivation, there is excessive service provision in the urban areas and this is perhaps a reflection of the service provision demanded by the urban population as a whole.

Service utilisation rates show that these are saturable in whatever circumstance they occur. One area of the city had higher rates of contact than the other (urban and rural) areas. One reason for lower levels of contacts in rural areas is the problem of travel for staff who cover a larger geographical area.

There are various interpretations for the findings as a whole: either the factors used are not applicable to rural populations, the factors do not predict psychiatric morbidity in rural populations or there are areas of unmet need in rural populations. Furthermore, this is a local study and only probably applicable to this locality. An alternative hypothesis is that the levels of 'need' in the rural and less deprived urban areas do not warrant large service input and that clients 'poach' places from more needy (urban) areas. However, the basic tenet of the National Health Service suggesting equal access to services as determined by need shows that these areas cannot be ignored. Indeed, as the situation currently stands, a client with a major mental illness in a rural area has two basic choices; to stay in his home environment and enjoy 'unmet' need or migrate to the inner areas of towns to experience an appropriate level of service. The paucity of services in rural areas will not be addressed without political will. As Wollet (1990) points out there are many factors involved and the problem will not be resolved by the market'. Caring for rural populations involves loss of the economies of scale and greater investment in time and money for mental health professionals to provide adequate care to rural residents.

\section{Acknowledgements}

We thank Mr Jonathan Wells, Ms Maggie Power, Mr Graham Badger and the Research Group at Cambridgeshire County Council for their invaluable assistance in preparing this piece.

\section{References}

Blazer, D., George, L., Landerman, R., et al (1985) Psychiatric disorders: a rural/urban comparison. Archives General Psychiatry 42, 651-656.

CAMBRIDGeshire County CouncIL (1996) Deprivation and Disadvantage in Cambridgeshire. Cambridge: The Research Group. Cambridge County Council.

Goodman, A., Siegal, C.. Craig. T., et al (1983) The relationship between socioeconomic class and the prevalence of schizophrenia, alcoholism and affective disorders treated as inpatients from a suburban area. American Journal of Psychiatry, 140, 166-170.

HARE, E. (1956) Mental illness and conditions in Bristol. Journal of Mental Science, 102, 349-357.

HIRsCH, S. (1988) Psychiatric Beds and Resources: Factors Influencing Bed Use and Service Planning. London: Gaskell.

JARMAN, B. (1983) Identification of underprivileged areas. British Medical Journal, 286, 1705-1709.

- (1984) Underprivileged areas; validation and distribution of scores. British Medical Journal, 289. 1587-1592.

Keatinge, C. (1989) Psychiatric admissions for alcoholism, neuroses and schizophrenia in rural and urban Ireland. International Joumal of Social Psychiatry. 34. 58-69.

Meltzer, H., GiLl, B., PetTiCRew, M. et al (1995) OPCS surveys of psychiatric morbidity. Report 1. The Prevalence of Psychiatric Morbidity Among Adults Living in Private Households. London: HMSO.

MUELLER, D. (1981) The current status for urban-rural differences in psychiatric disorder: an emerging trend for depression. Journal of Nervous and Mental Disorders, 169, 18-27.

PHILLIMORE, P. \& READING, R. (1992) A rural advantage? Urban-rural health differences in Northern England. Journal of Public Health Medicine, 14, 290-299.

Romans-Clarkson, S., Walton, V., Herbison, P., et al (1990) Psychiatric morbidity and women in urban and rural New Zealand: psychosocial correlates. British Journal of Psychiatry, 156, 84-91.

RURAL DEVELOPMENT COMmission (1994) Rural Development Areas 1994. London: Department of Environment.

Stansfield, S. A., LeEk, C. A., Travers, W., et al (1992) Attitudes to community psychiatry among urban and rural general practitioners. British Journal of General Practice, 42, 322-325.

THORNICROFT, G. (1991) Social deprivation and rates of treated mental disorder. British Journal of Psychiatry. 158, 475-484.

-. BISOFFI, G., DE SALVIA, D., et al (1993) Urban-rural differences in the associations between social deprivation and psychiatric service utilisation in schizophrenia and all diagnoses: a case-register study in northern Italy. Psychological Medicine, 23. 487-496.

Vázguez-Barguero, J. l., Herrera Castanedo, S., Artal. J. A., et al (1993) Pathways to psychiatric care in Cantabria. Acta Psychiatrica Scandinavia, 88, 229-234.

-. FRANKS, A. J. \& SHELDON, T. A. (1993) Rural health and health care (editorial). British Medical Journal, 306. 1358-1359.

Wollet, S. (1990) Counting The Rural Cost: The Case For A Rural Premium. London: NCVO.

A. J. Smith, Senior Registrar, and *R. Ramana, Consultant, Box 35, Addenbrooke's Hospital, Hills Road, Cambridge CB2 $29 Q$

*Correspondence 